\title{
Clinical study of maternal complications associated with eclampsia
}

\author{
Bhanu B. T.*, Amudha S., Sarojini
}

Department of Obstetrics and Gynecology, Bangalore Medical College and Research Institute Bangalore, Karnataka, India

Received: 19 February 2017

Accepted: 24 March 2017

\author{
*Correspondence: \\ Dr. Bhanu B. T., \\ E-mail: docbhanubt@gmail.com
}

Copyright: () the author(s), publisher and licensee Medip Academy. This is an open-access article distributed under the terms of the Creative Commons Attribution Non-Commercial License, which permits unrestricted non-commercial use, distribution, and reproduction in any medium, provided the original work is properly cited.

\begin{abstract}
Background: Eclampsia is still one of the leading causes of maternal mortality and morbidity in developing countries. Though the incidence in developed nations has drastically reduced, it has remained the same over years in India, mainly due to lack of awareness, poor socio-economic status and inadequate ante natal check-ups. The objective of this study was to determine the presentation, demographic features, risk factors, management, maternal mortality and morbidity, in women presenting with eclampsia.

Methods: This study was conducted in Vanivilas hospital from January to December 2014 for 12 months. Total 230 women with eclampsia were studied with respect to their age, parity, socio economic status, gestational age, details of previous antenatal check-ups, clinical features at presentation, nature and number of convulsions, treatment received before admission, management in the institution and maternal morbidity and mortality.

Results: The incidence of Eclampsia was 1.4\%. 30\% were below 20 years of age, $45 \%$ were primigravidas, $97 \%$ were referred cases with inadequate antenatal checkups. $68 \%$ had antepartum eclampsia, $22 \%$ had intrapartum eclampsia and $10 \%$ had postpartum eclampsia. $24 \%$ had instrumental delivery, $24 \%$ underwent caesarean delivery. There were $17.4 \%$ ICU admissions, 5.7\% acute kidney injury cases and 13 maternal deaths.

Conclusions: Eclampsia still remains a major cause of maternal morbidity and mortality in india. Information about danger signs of pre-eclampsia/ eclampsia should be made available to antenatal clients. Importance of timely referral to the tertiary center should be emphasised to the peripheral health workers.
\end{abstract}

Keywords: Acute kidney injury, ECLAMPSIA, HELLP, Maternal complications, Pulmonary edema

\section{INTRODUCTION}

Hypertensive disorders complicating pregnancy are one of the deadly triad, along with haemorrhage and infection that contribute greatly to maternal mortality and morbidity. These hypertensive disorders remain among the most unsolved problems in obstetrics. This hypertensive disorder of pregnancy consists of a spectrum of disorders from gestational hypertension, preeclampsia, eclampsia, pre-eclampsia superimposed on chronic hypertension and chronic hypertension.

Preeclampsia is described as pregnancy specific syndrome that can affect virtually every organ system. It is diagnosed with a minimum criterion of $\mathrm{BP} \geq 140 / 90 \mathrm{~mm}$ of $\mathrm{Hg}$ after 20 weeks of gestation and proteinuria of $\geq 300$ $\mathrm{mg} / 24$ hours or $\geq 1+$ dipstick. Preeclampsia complicated by generalised tonic - clonic convulsions is termed eclampsia. Fatal coma without convulsions has also been called eclampsia. Once eclampsia has ensued, the risk to both mother and fetus increase significantly. Major complications include placental abruption, neurological deficits, aspiration pneumonia, pulmonary edema, acute renal failure, HELLP syndrome, DIC, cardiopulmonary arrest and maternal death. ${ }^{2}$

In $10 \%$ women, some degree of blindness follows a seizure. Two causes for impaired vision or blindness are 
varying degrees of retinal detachment or occipital lobe ischemia or edema. In these cases, the vision returns to normal within a week. ${ }^{3}$ Rarely permanent visual defects including blindness develop due to cerebral infarction or retinal artery infarction and ischemia.,

Eclampsia is a preventable and treatable cause of maternal morbidity and mortality with poor feto-maternal outcome in developing countries. In India, it is the one of the most common causes of maternal mortality. The high maternal morbidity and mortality due to eclampsia in the developing countries has been ascribed to late referral, delay in hospitalization, lack of transport, unbooked status of patients and multiple seizures prior to admission. We are being a tertiary care centre get many cases of eclampsia. Hence this study is undertaken.

\section{METHODS}

This is a cross sectional observational study conducted at Vanivilas hospital from January 2014 to December 2014 for 12 months.

Objective of this study was to determine the presentation, demographic features, risk factors, management, maternal mortality and morbidity, in women presenting with eclampsia.

There were 230 women with eclampsia who developed convulsions before, at or after admission during this study period. Details of their age, parity, socio economic status, gestational age, number of previous antenatal check-ups, clinical features at presentation, nature and number of convulsions, whether a known case of HDP, treatment received before admission, detailed history of current pregnancy and previous pregnancies were documented. Women were subjected to a detailed clinical examination.

The $\mathrm{MgSO}_{4}$ regimen and antihypertensive management, mode of termination of pregnancy, duration of hospitalisation noted. An analysis of maternal mortality and morbidity was done with respect to ICU admissions, development of status eclampticus, cerebral complications like PRESS syndrome (posterior reversible encephalopathy syndrome), intraventricular haemorrhage, cerebral edema, blindness, HELLP (haemolysis, elevated liver enzymes, low platelets) syndrome, DIC (disseminated intravascular coagulation), acute kidney injury, pulmonary edema and maternal deaths. Cases were followed up throughout the period of their hospitalization till discharge.

\section{RESULTS}

The following data was obtained from the present study. During the study period there were 16,361 deliveries, of which $1.4 \%$ were complicated with ECLAMPSIA.
The age distribution of present study group is shown in Table 1. Nearly $40 \%$ women were below 20 years and $50 \%$ were between 20 and 30 years of age.

Table 1: Age distribution.

\begin{tabular}{|lll|}
\hline Age & Number & Percentage \\
\hline$<-19$ & 94 & 40.8 \\
\hline $20-24$ & 68 & 29.5 \\
\hline $25-29$ & 48 & 20.8 \\
\hline$>-30$ & 20 & 8.6 \\
\hline
\end{tabular}

In the present series, there were $104(45 \%)$ primis, 55 (24\%) second gravidas, $41(18 \%)$ third gravidas, 28 (12\%) fourth gravidas and $2(1 \%)$ fifth gravidas. Nearly half of the women in this study group were primigravidas.

Table 2: Gestational age at the onset of antepartum convulsions.

\begin{tabular}{|lll|}
\hline GA & Number & Percentage \\
\hline $28-34$ & 60 & 26 \\
\hline $34-37$ & 110 & 48 \\
\hline$>37$ & 60 & 26 \\
\hline
\end{tabular}

Table 2 shows, gestational age at the onset of convulsions. It includes both antepartum and intrapartum cases. $48 \%$ of the patients were between 34 and 37 weeks of gestation.

Among 230, 223 (97\%) cases were referred cases. Almost all 230 women belonged to low socioeconomic status.

$124(54 \%)$ were diagnosed as cases of pre-eclampsia before convulsions, out of which 83 (36\%) were on antihypertensives.

Out of $106(46 \%)$ who were not diagnosed as HDP prior to convulsions, 67 (29\%) did not have an ANC visit for one month prior to convulsions.

$157(68 \%)$ had antepartum eclampsia, 50 (22\%) had intrapartum eclampsia and $23(10 \%)$ had postpartum eclamsia.

$4(1.7 \%)$ had chronic renal disease prior to pregnancy, 3 $(1.3 \%)$ had chronic hypertension.

$80(34.0 \%)$ patients out of the 223 referred patients had received loading dose of $\mathrm{MgSO} 4$, that is $4 \mathrm{gm} \mathrm{IV}$ and 10 gm IM according to Pritchard regime. 50 (21.7\%) patients had got only $10 \mathrm{gm} \mathrm{IM} \mathrm{MgSO}_{4} .10(4.3 \%)$ patients had received $10 \mathrm{mg}$ diazepam IV and $83(36 \%)$ of them had not received any anticonvulsive treatment.

$224(97.4 \%)$ of them received Pritchard regimen $\mathrm{MgSO}_{4}$. $6(3.6 \%)$ of them were given IV MgSO4 i.e Zuspan 
regimen as their platelet count was low contraindicating intramuscular injections. Out of 224 cases who received Pritchard regimen 24 could not take the drug as prescribed either due to inadequate urine output (21 cases) or due to toxicity (3 cases).

Table 3: Mode of delivery.

\begin{tabular}{|lll|}
\hline Delivery & Number & Percentage \\
\hline Vaginal & 175 & 76 \\
\hline Non-instrumental & 120 & 52 \\
\hline Forceps & 46 & 20 \\
\hline Vacuum & 9 & 4 \\
\hline Cesarean section & 55 & 24 \\
\hline
\end{tabular}

$175(76 \%)$ delivered vaginally and $55(24 \%)$ underwent caesarean delivery.

Out of 175 vaginal deliveries 46 (20\%) underwent forceps delivery and $9(4 \%)$ had ventouse assisted delivery as shown in Table 3 .

Maternal complications are noted down in Table 4. Placental abruption was the most common complication $(15.7 \%)$ followed by DIC $(5.7 \%)$.

There were 40 (17.4\%) ICU admissions and $13(5.7 \%)$ maternal deaths. Out of 13 deaths 4 (1.6\%) had cerebrovascular accidents, $2(0.8 \%)$ had acute pulmonary edema, $2(0.8 \%)$ had disseminated intravascular coagulation with multi organ dysfunction, $2(0.8 \%)$ had HELLP syndrome with anemia with DIC, $1(0.4 \%)$ had acute pulmonary embolism, $1(0.4 \%)$ had septicaemia with multiorgan dysfunction and $1(0.4 \%)$ had acute kidney injury with uremic encephalopathy.

Table 4: Maternal complications.

\begin{tabular}{|lll|}
\hline Complications & Number & Percentage \\
\hline Placental abruption & 36 & 15.7 \\
\hline DIC & 13 & 5.7 \\
\hline Press syndrome & 6 & 2.6 \\
\hline CVA & 4 & 1.7 \\
\hline Acute kidney injury & 7 & 3 \\
\hline Blindness & 3 & 1.3 \\
\hline HELLP syndrome & 28 & 12.1 \\
\hline Pulmonary edema & 4 & 1.7 \\
\hline Pulmonary embolism & 1 & 0.4 \\
\hline PPH & 9 & 3.9 \\
\hline Maternal deaths & 13 & 5.7 \\
\hline
\end{tabular}

\section{DISCUSSION}

In our study $1.4 \%$ of pregnancies were complicated with eclampsia. It is higher than the prevalence rate of $0.76 \%$ found in the study conducted by Ajah LO and collegues. ${ }^{6}$ Higher prevalence might be attributed to the fact that ours is a tertiary care centre which acts as a referral hospital covering a large area.

In present study $40 \%$ of women were below 20 years of age which is comparable to the study done by Ghimire $\mathrm{S}$ where $41 \%$ of women were less than 19 years of age. ${ }^{7}$ This finding substantiates the fact that preeclampsia with severe features and eclampsia is more common among adolescents.

Table 5: Comparison of maternal complications with other studies.

\begin{tabular}{|llllll|}
\hline Complications & Present study & Aqida & Ghimire S & Minire A & Nankali A \\
\hline ARF & $3 \%$ & $10.1 \%$ & - & $12.3 \%$ & $8 / 349$ \\
\hline Visual impairment & - & $1.7 \%$ & - & - & $13 / 349$ \\
\hline HELLP syndrome & $12.1 \%$ & - & - & $24 / 430$ & $1 /$ \\
\hline Pulmonary edema & - & - & - & $12 / 430$ & $37 /$ \\
\hline DIC & - & - & - & $30 / 430$ & $27 / 349$ \\
\hline Placental abruption & - & - & - & - & - \\
\hline Maternal deaths & $5.7 \%$ & - & $5.36 \%$ & & - \\
\hline
\end{tabular}

In present study $45 \%$ were primis, which is comparable with the study conducted by Ghimire $\mathrm{S}$ and Aqida ET and collegues. ${ }^{7,8}$ In present study $97 \%$ were referred cases and almost all 230 women belonged to low socioeconomic status. 29\% did not have any ANC visit prior to convulsions. These findings substantiate the fact that eclampsia is more common in poor and unbooked primiparas. Antepartum eclampsia $(68 \%)$ was more than intra-partum $(22 \%)$ and postpartum (10\%) combined. Similar results were found in a study conducted by Aqida and collegues in Nigeria. ${ }^{8} 224$ women were given Pritchard regimen $\mathrm{MgSO} 4$ and other 6 Zuspan regimen to manage convulsions, as Magnesium sulphate is currently the most ideal drug for the treatment of eclampsia to control convulsions. ${ }^{9}, 10$

Eclamptic fits were more common (48\%) in 34-37 weeks period of gestation. Fits to delivery interval was more than six hours in $89.1 \%$ women and $24 \%$ women underwent caesarean delivery, $20 \%$ cases underwent forceps delivery and $4 \%$ had ventouse delivery. These 
rates are higher compared to average hospital statistics. Comparison of maternal complications with other studies is shown in Table 5. From all the studies mentioned in the table it can be stated that eclampsia is the most common medical complication of pregnancy and is associated with substantial morbidity and mortality for mother.

\section{CONCLUSION}

Eclampsia is common among the adolescents, unbooked and low socio-economic group of women in this study. Eclampsia still remains a major cause of maternal morbidity and mortality in India. More awareness and enabling factors should be created for more women to access antenatal facilities. Information about danger signs of pre-eclampsia / eclampsia should be made available to antenatal clients. Significant efforts are required towards female education, women empowerment and provision of social amenities in rural areas. There is a need to educate the women especially of lower socio economic classes regarding nutrition, pregnancy and the need for regular Ante natal check-ups.

Funding: No funding sources Conflict of interest: None declared

Ethical approval: The study was approved by the Institutional Ethics Committee

\section{REFERENCES}

1. Cunnigham, Leveno, Bloom, Hauth, Rouse, Spong. Pregnancy hypertension. Williams Obstetrics, 23rd ed. Mc Graw Hill; 2010:706-56.

2. Matter F, Sibai BM, Eclampsia: VIII. Risk factors for maternal morbidity. Am J Obstet Gynecol. 2000;182:307.

3. Cunningham FG, Fernandez CO, Hernandez C. Blindness associated with preeclampsia and eclampsia. Am J Obstet Gynecol. 1995;172:1291.
4. Lara Torre E, Lee MS, Wolf MA, Shah DM. Bilateral retina 1 occlusion progressing to long standing blindness in severe preeclampsia. Obstet Gynecol. 2002;100(5 Pt 1):940-2.

5. Moseman CP, Shelton S. Permanent blindness as a complication of pregnancy induced hypertension. Obstet Gynecol. 2002;100:943.

6. Ajah LO, Ozonu NC, Ezeonu PO, Lawani LO, Obuna JA, Onwe EO. The feto-maternal outcome of preeclampsia with severe features and eclampsia in Abakaliki, South-East Nigeria. J Clin Diagn Res. 2016;10(9):QC18-QC21.

7. Ghimire S. Eclampsia: feto-maternal outcomes in a tertiary care centre in Eastern Nepal. J Nepal Med Assoc. 2016;54(201):24-8.

8. Agida ET, Adeka BI, Jibril KA. Pregnancy outcome in eclamptics at the University of Abuja Teaching Hospital, Gwagwalada, Abuja: a 3 year review. Niger J Clin Pract. 2010;13(4):394-8.

9. Chama CM, Geidam AD, Bako B, Mairiga AG, Atterwahmie A. A shortened versus standard matched postpartum magnesium sulphate regimen in the treatment of eclampsia: a randomised controlled trial. Afr J Reprod Health. 2013;17(3):131-6.

10. Regmi MC, Aggrawal A, Pradhan T, Rijal P, Subedi A, Uprety D. Loading dose versus standard regimen of magnesium sulphate in eclampsia: a randomized trial. Nepal Med Coll J. 2010;12(4):244-7.

11. Minire A, Mirton M, Imri V, Lauren M, Aferdita M. Maternal complications of preeclampsia. Med Arch. 2013;67(5):339-41.

12. Nankali A, Malek-khosravi SH, Zangeneh M, Rezaei M, Hemati Z, Kohzadi M. Maternal complications associated with severe preeclampsia. J Obstet Gynaecol India. 2013;63(2):112-5.

Cite this article as: Bhanu BT, Amudha S, Sarojini. Clinical study of maternal complications associated with eclampsia. Int J Reprod Contracept Obstet Gynecol 2017;6:1905-8. 